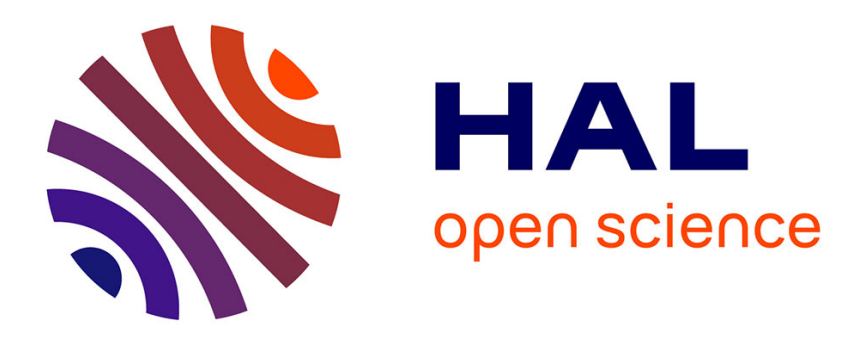

\title{
Multivariate ALCHEMI in the presence of anti-site defects
}

M. Walls

\section{To cite this version:}

M. Walls. Multivariate ALCHEMI in the presence of anti-site defects. Journal de Physique IV Proceedings, 1993, 03 (C7), pp.C7-2155-C7-2158. 10.1051/jp4:19937342 • jpa-00251990

\section{HAL Id: jpa-00251990 https://hal.science/jpa-00251990}

Submitted on 1 Jan 1993

HAL is a multi-disciplinary open access archive for the deposit and dissemination of scientific research documents, whether they are published or not. The documents may come from teaching and research institutions in France or abroad, or from public or private research centers.
L'archive ouverte pluridisciplinaire HAL, est destinée au dépôt et à la diffusion de documents scientifiques de niveau recherche, publiés ou non, émanant des établissements d'enseignement et de recherche français ou étrangers, des laboratoires publics ou privés. 


\title{
Multivariate ALCHEMI in the presence of anti-site defects
}

\author{
M.G. WALLS \\ CNRS, Centre d'Etudes de Chimie Métallurgique, 15 rue Georges Urbain, 94407 Vitry-sur-Seine cedex, \\ France
}

\begin{abstract}
It is shown that a recently developed formulation of ALCHEMI, which takes into account the $\mathrm{x}$-ray signal delocalisation effects, is not suitable for adaptation to the case of anti-site defect density determinations. However, the multivariate formulation of the method ALCHEMI is then applied to an Ni-Fe-Cr ordered alloy sample containing significant numbers of anti-site defects, and whose site distributions for all three elements were known in advance. In this way the importance of the presence of such defects is quantitatively determined for a real case. It is found that for this sample, the errors introduced are less than those arising from other sources, and it appears likely that in general the method can tolerate fairly high defect levels for compounds of host stoichiometry $A_{x} B$ where $x$ is 3 or higher.
\end{abstract}

\section{Introduction}

Atom Location by Channelling Enhanced Microanalysis (ALCHEMI) is a method for determining the distribution of an additional element on the host sites in a crystal. It uses standard energy dispersive $\mathrm{x}$-ray (EDX) spectra acquired with different sample orientations, and hence different channelling conditions. Using the host signal changes with orientation as a reference for the change in electron intensity on a given type of site, the changes in the additional element's signal yield the distribution of that element on the host sites $[1,2]$. The method assumes that the host elements reside exclusively on their own sites, and so the presence of large numbers of anti-site defects could lead to inaccuracies. Previous attempts have been made to solve the problem but some require a priori knowledge of the distribution of at least one element,eg. [3] and others can be applied only to layered structures eg. [4].

Another problem with ALCHEMI is "delocalisation", ie. the large impact parameters associated with the excitation of low energy $x$-rays by fast electrons, since this tends to cancel the channelling effect, leading to difficulties in the case of materials containing light elements whose $\mathrm{x}$-rays are of low energy. Recently multivariate formulations of the method have been developed which are less sensitive to this phenomenon $[5,6]$, and it was thought that a similar treatment might be used to solve the anti-site defect problem. In this paper it is shown that the delocalisation formulation cannot in fact be adapted in this way, but that the potential problems arising from anti-site defects are in certain circumstances not very severe.

\section{The multivariate formulation in the presence of anti-site defects}

Consider a material with two host elements A and B (which in the perfectly ordered material reside on sites $a$ and $b$ respectively) and one added or impurity element, $C$ (generalisations to more complex systems are straightforward). It is assumed that the stoichiometry of the sample $\left(A_{f_{A}} B_{f_{B}} C_{f_{C}}\right.$ with $\left.f_{A}+f_{B}+f_{C}=1\right)$ and the EDX $k$-factors for the elements concerned are known, although in fact the stoichiometry as measured by a 
standard EDX analysis using approximate $k$-factors will suffice - the errors in the ' $\mathrm{k}$ 's cancelling those in the 'f's in the analysis. Let $\varepsilon_{\mathrm{A}, \mathrm{B}}$ be the fraction of element $\mathrm{A}, \mathrm{B}$ which is on its anti-site, and $\mathrm{p}_{\mathrm{a}}$ the fraction of element $\mathrm{C}$ which is on site type a - this is what we wish to find. Let $\mathrm{N}_{\mathbf{X}}$ be the spectrum counts for element $X, t$ the time of exposure, $N_{\text {at }}$ the total no of atoms under the beam, $|\Psi|^{2}$ the average fast electron intensity on sites of type $x$ and $K_{X}$ the $X$-ray counts per atom $X$ per unit fast electron dose. The reduced signals $I_{X}=N_{X} / f_{X} K_{X} t N_{a t}$ for the three elements present can then be written

$$
\begin{aligned}
& \mathrm{I}_{\mathrm{A}}=\left(1-\varepsilon_{\mathrm{A}}\right)|\Psi|_{\mathrm{a}}^{2}+\varepsilon_{\mathrm{A}}|\Psi|_{\mathrm{b}}^{2} \\
& \mathrm{I}_{\mathrm{B}}=\varepsilon_{\mathrm{B}}|\Psi|_{\mathrm{a}}^{2}+\left(1-\varepsilon_{\mathrm{B}}\right)|\Psi|_{\mathrm{b}}^{2} \\
& \mathrm{I}_{\mathrm{C}}=\mathrm{p}_{\mathrm{a}}|\Psi|_{\mathrm{a}}^{2}+\left(1-\mathrm{p}_{\mathrm{a}}\right)|\Psi|_{\mathrm{b}}^{2}
\end{aligned}
$$

Eliminating the $|\Psi|^{2}$ we can write

$$
I_{C}=p_{a}\left[\frac{I_{B} \varepsilon_{A} /\left(1-\varepsilon_{B}\right)-I_{A}}{\varepsilon_{A} \varepsilon_{B} /\left(1-\varepsilon_{B}\right)+\varepsilon_{A}-1}\right]+\left(1-p_{a}\right)\left[\frac{I_{A} \varepsilon_{B} /\left(1-\varepsilon_{A}\right)-I_{B}}{\varepsilon_{A} \varepsilon_{B} /\left(1-\varepsilon_{A}\right)+\varepsilon_{B}-1}\right]
$$

Following [6] this expression is rearranged to give $I_{C}$ as a linear combination of $I_{A}$ and $I_{B}$

$$
I_{C}=\left[\frac{p_{a}-\varepsilon_{B}}{1-\varepsilon_{A}-\varepsilon_{B}}\right] I_{A}+\left[\frac{1-p_{a}-\varepsilon_{A}}{1-\varepsilon_{A}-\varepsilon_{B}}\right] I_{B}
$$

or

$$
\mathrm{I}_{\mathrm{C}}=\mathrm{XI}_{\mathrm{A}}+\mathrm{YI}_{\mathrm{B}}
$$

Note that $X+Y=1$. Thus in principle if one plots $I_{C}$ on the $z$ axis against $I_{A}$ and $I_{B}$ on the $X$-and $y$-axes for a series of spectra acquired using a fixed dose on a fixed volume of sample but at different orientations, the data should lie in a plane with slopes $X$ and $Y$ on the $x$ - and $y$-axes. $K_{C} / K_{A, B}=k_{C A, B}$, the EDX $k$ factor for the two elements, so in practice the real signals could be used: $\mathrm{N}_{C}$ would be plotted against $N_{A} f_{A} / f_{C} k_{C A}$ and $N_{B} f_{B} / f_{C} k_{C B}$. From eqns. (1) and (2) we can write

$$
\begin{aligned}
& X \varepsilon_{A}+(X-1) \varepsilon_{B}+p_{a}=X \\
& (Y-1) \varepsilon_{A}+Y \varepsilon_{B}-p_{a}=Y-1
\end{aligned}
$$

Making the assumption that the interstitial and vacancy densities are negligible (this applies to all ALCHEMI formulations) a further relation exists between the occupation factors, which may be written

or

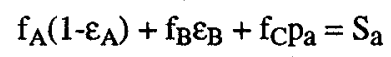

$$
-f_{A} \varepsilon_{A}+f_{B} \varepsilon_{B}+f_{C} p_{a}=S_{a}+f_{A}
$$

Equations (3), (4) and (5) appear to form a simple linear set which could be solved for $\varepsilon_{A}, \varepsilon_{B}$ and $\mathrm{pa}_{a}$, but in fact the determinant of the coefficient matrix is $1-X-Y=0$, and so no unique solution exists. The physical reason for this is that there is no way of distinguishing between say, (a) strong channelling on one site in a sample with a large anti-site defect density and a fairly uniform impurity distribution, and (b) weak channelling on one site in a sample with low defect density and a more site-dependent impurity distribution. Both may give the same relative changes in the host and impurity signal intensities. This difficulty could be overcome if the channelling condition could be known with certainty for each spectrum, but one of the main points of ALCHEMI is precisely the avoidance of the necessity of knowing such details. Similar arguments apply to the problem of using simple ALCHEMI to determine the order parameter in, for example, a binary alloy. 


\section{Experimental test of ALCHEMI in the presence of large anti-site defect concentrations}

In order to gauge in a real situation the magnitude of the errors introduced by the presence of anti-site defects, a multivariate ALCHEMI measurement was carried out on an ordered ternary alloy with the $\mathrm{Ll}_{2}$ structure, for which the distributions of the elements on the two distinct sites was already known from anomalous $\mathrm{x}$-ray diffraction (AXD) experiments $[7,8]$. The sample composition was $\left(\mathrm{Ni}_{3} \mathrm{Fe}\right)_{0.964} \mathrm{Cr}_{0.036}$ and its preparation is described in $[7,8]$. The microscope samples were prepared from the sheet metal by electro-polishing. The microscope used was a JEOL $2000 \mathrm{FX}$ operating at $80 \mathrm{kV}$, and the $\mathrm{x}$-ray spectrometer was a Seph Be window model controlled by a Tracor computer. The sample was cooled to $105 \mathrm{~K}$ in a Gatan liquid nitrogen holder to increase the channelling effects. 25 spectra were acquired for 100 s each from the same area of sample at various orientations around (111) within $\pm 5^{\circ}$. Further experimental details were as in [6]. The analysis was then carried out following ref.[5] or [6], ie. a least squares routine finds the best planefit coefficients when $N_{C}$ is plotted against $N_{A}+N_{B}$ assuming no antisite defects are present. Since $\mathrm{Cr}(\mathrm{Z}=24)$ is the lightest element present and the operating voltage was $80 \mathrm{kV}$ it was also assumed that delocalisation effects were negligible [9].

\section{Results and discussion}

Figure 1 shows a plot of the adjusted counts for $\mathrm{Ni}$ and $\mathrm{Fe}$ (ie, multiplied by the relevant $\mathrm{f}_{\mathrm{X}} / \mathrm{f}_{\mathrm{Cr}} \mathrm{k}_{\mathrm{CrX}}$ and the coefficients found in the planefit) against those for $\mathrm{Cr}$ in each spectrum. It can be seen that the sum fits a straight line quite well (correlation coefficient $=0.98$ ). Note also that the Fe signal changes relatively little, so that the gradient along the $\mathrm{Fe}$ axis in a 3-D plane-plot is relatively ill defined. Equations 3 and (4) show that when $\varepsilon_{A}=\varepsilon_{B}=0$ the gradient on either axis can be used to yield $p_{a}$, so we choose in this case to use that along the $\mathrm{Ni}$ axis, and the results are given in table 1 . The uncorrected result is already in agreement within the limits of experimental error with that from [7]. However, it was known from [7] and [8] that in fact about $8 \%$ of the $\mathrm{Ni}$ (and incidentally about $27 \%$ of the $\mathrm{Fe}$ ) is actually on its anti-site in this material. This means that the value of $\mathrm{f}_{\mathrm{Ni}}$ used in determining the adjusted $\mathrm{Ni}$ counts could be replaced by a value $8 \%$ lower, leading to a coresponding increase in the gradient on that axis and consequently in $\mathrm{pa}$. Since the Fe signal changes very little it can be assumed that the strength of channelling on the Fe type sites did not change very much, and so the $\mathrm{Ni}$ atoms on the Fe sites should contribute a relatively uniform background to the Ni signal. This should not greatly affect the analysis, which uses only gradients, ie. changes in signal. Thus an anti-site defect-corrected value for the $\mathrm{Cr}$ fraction on $\mathrm{Ni}$ sites is included in the table, and agrees a little more closely with the AXD result, but the errors arising from other experimental factors, mostly the statistics of the spectra in this case, are in any case $\pm 9 \%$.

Of course the anti-site defect density is not normally known a priori and so this procedure cannot be used in general to improve ALCHEMI accuracy. It is included here only to show that the error introduced by the anti-site defects is quite likely to be only of the same order as that from the normal sources. Note that if the defect concentration were higher, say $16 \%$ of the Ni on Fe sites, this would imply that nearly half the $\mathrm{Fe}$ was not on its own site. In those circumstances the sample could hardly be considered ordered, and an ALCHEMI measurement would cease to have much meaning anyway. Diffraction methods should indicate when this is the case. This argument applies to all samples of host stoichiometry 3:1 or higher, and so reasonably reliable ALCHEMI should prove possible if an axis can be found about which the signal of the majority element changes much more than that of the minority element, as was the case here.

When the perfect stoichiometry is $\mathrm{AB}$ or $\mathrm{A}_{2} \mathrm{~B}$ there will be relations of the type in equation (5) between the defect concentration and the stoichiometry. It thus seems possible that iterative methods might be used to solve such cases, starting from the assumption that there are no anti-site defects, and converging on the real concentrations. This topic is currently under investigation.

\section{Conclusions}

Although the simple multivariate approach to ALCHEMI cannot be directly applied to the solution of the problem of anti-site defects, it seems that the errors caused by such defects are typically only of the same order as those arising from the usual statistical considerations, especially if the perfect host stoichiometry is of type $A_{X} B$ where $X$ is 3 or greater. 
I am grateful to Mme. Y. Calvayrac for providing the sample.

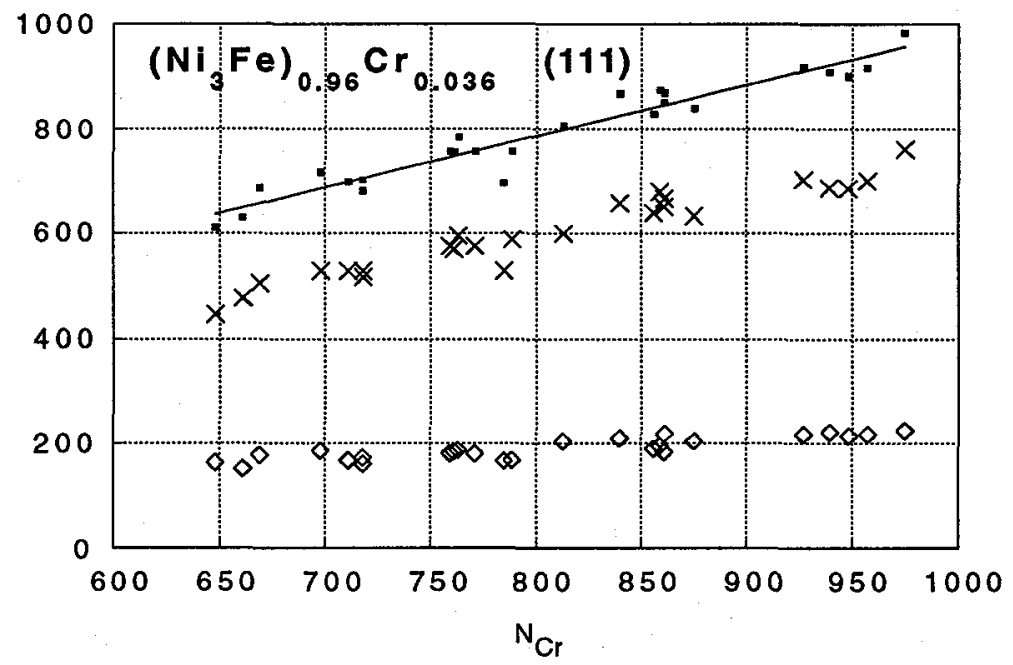

Figure 1. Adjusted counts for $=\mathrm{Ni}$ (crosses) and $\mathrm{Fe}$ (diamonds) and their sum (squares) against $\mathrm{Cr}$ counts

Table 1. Site occupation of $\mathrm{Cr}$ atoms in $\left(\mathrm{Ni}_{3} \mathrm{Fe}\right)_{0.964} \mathrm{Cr}_{0.036}$

\begin{tabular}{|c|c|}
\hline Experimental method & Percentage of Cr lying on Ni type sites \\
\hline $\begin{array}{c}\text { ALCHEMI } \\
\text { (no anti-site correction) }\end{array}$ & $56.7 \pm 9$ \\
\hline $\begin{array}{c}\text { ALCHEMI } \\
\text { (with anti-site correction) }\end{array}$ & $61.1 \pm 9$ \\
\hline AXD [7] & $64.1 \pm 12$ \\
\hline
\end{tabular}

\section{References}

[1] Spence J. and Taftø J., J.Microscopy (1983) 130, 147

[2] Taftø J., J. Appl. Cryst. (1982) 15,378

[3] Matsumura S.,Morimura T., and Oki K. Mater. Trans. JIM. (1991) 32905

[4] Krishnan K.M. and Thomas G., J. Microsc. (1984) 13697

[5] Rossouw C.J., Turner P.S., White T.J. and A.J. O'Connor A.J., Phil. Mag. Lett. (1989) 60, 225

[6] Walls M.G. Microsc. Microanal. Microstruct. (1992) 3443

[7] Marty A., Ph.D.Thesis (1990) Université Paris VI, France

[8] Marty A., Bessière M., Bley F., Calvayrac Y. and Lefebvre S., Acta Metall. Mater. (1990) 38, 345

[9] Pennycook S.J., Ultramicroscopy (1988) 26, 239 